\title{
Proximidade setorial na indústria de transformação brasileira
}

Sectoral proximity in the Brazilian manufacturing industry

\author{
Milene Simone Tessarin (1) \\ Paulo César Morceiro (1) \\ André Luiz Squarize Chagas (2) \\ Joaquim José Martins Guilhoto(2,3)
}

\author{
(1) DST/NRF South African Research \\ Chair in Industrial Development, \\ University of Johannesburg \\ (2) Universidade de São Paulo \\ (3) Organização para Cooperação e \\ Desenvolvimento Econômico
}

\begin{abstract}
This study evaluates the proximity in productive and technological terms between 100 manufacturing sectors, offering a new measure of cognitive proximity. There are three contributions: an unprecedented neighborhood matrix created with information on multiproduct plants; a new index that captures productive and technological skills related to worker's occupation; and a method of spatial econometrics were used in an innovative way to evaluate the sectoral proximity. Was used unpublished information from a special tabulation of PIA-Empresa/IBGE. Statistical analyzes confirmed the existence of proximity between manufacturing sectors verified through the productive and technological skills of workers. The neighborhood network was denser among sectors that have occupations with similar skills and between sectors of the same technological level. Proximity sectoral spillovers were found in the form of positive marginal effects on productivity and investment.
\end{abstract}

\section{Keywords}

sectoral proximity, manufacturing industry, productive base, technological base, worker skills.

JEL Codes L25, L60, O33, J24, R15.

\section{Resumo}

Este estudo avalia a proximidade em termos produtivos e tecnológicos entre 100 setores manufatureiros, oferecendo uma nova medida de proximidade cognitiva. Há três contribuições: criou-se uma matriz de vizinhança setorial inédita com informações de plantas industriais multiprodutos; elaborou-se um novo indice que capta habilidades produtivas e tecnológicas relacionadas às ocupações dos trabalhadores; e empregou-se, de modo inovador, métodos de econometria espacial para avaliar a proximidade setorial. Adotaram-se informações inéditas de uma tabulação especial da PIA-Empresa/IBGE. Análises estatísticas confirmaram a existência de proximidade entre setores manufatureiros verificada através das habilidades produtivas e tecnológicas dos trabalhadores. A rede de vizinhança mostrou-se mais densa entre setores que possuem ocupações com habilidades semelhantes e entre setores do mesmo nivel tecnológico. Encontraram-se spillovers setoriais da proximidade na forma de efeitos marginais positivos sobre produtividade e investimento.

\section{Palavras-chave}

proximidade setorial, manufatura, base produtiva, base tecnológica, habilidades dos trabalhadores.

Códigos JEL L25, L60, O33, J24, R15. 


\section{Introdução}

O debate sobre proximidade cognitiva vem ganhando diferentes abordagens recentemente. Pesquisadores buscam entender como a relação entre atividades produtivas afeta o desempenho das economias e como a presença de uma pauta produtiva diversificada pode ajudar países a saírem de crises ou a inovar, por exemplo. A literatura aponta três formas de se medir a proximidade: via classificações setoriais, que evidenciam quais setores possuem economias de escopo; pela coocorrência de setores no portfólio de produção de uma empresa ou de produtos exportados; e por índices baseados em recursos, que capturam similaridades nos recursos usados em diferentes setores (ver seção 2.1 sobre essas formas). Como os trabalhadores fazem parte dos recursos produtivos das empresas, as habilidades retidas pelos indivíduos são consideradas um fator-chave para a evidência de proximidade. $\bigcirc$ estoque de conhecimento acumulado através de educação formal e experiência torna-se também um ativo das empresas (Farjoun, 1994). O capital humano interliga conhecimentos e tecnologias gerados interna e externamente através da absorção de transbordamentos, além de contribuir com novas ideias e para a produção (Teece et al., 1992).

Segundo Rodrik (2016), a sociedade moderna é sob muitos aspectos produto da industrialização. No Brasil, o período de maior crescimento do PIB - anos 1930 a 1980 - esteve atrelado à instalação e expansão do setor manufatureiro, e embora na década de 1980 o ritmo de crescimento tenha reduzido, o emprego industrial e o número de áreas industriais no país cresceram (Diniz; Crocco, 1996). Nos anos 2000, a base industrial novamente se expandiu, em um terço (Morceiro, 2018). Segundo esse autor, o Brasil possui uma base industrial diversificada e figura entre os 15 maiores parques industriais do planeta. Os setores da manufatura têm elevado encadeamento com os demais setores de atividade, assim, quando a manufatura cresce ela contribui mais que proporcionalmente (ao seu tamanho) para o crescimento do PIB.

Neste artigo a preocupação foi estabelecer uma medida de proximidade setorial entre os 100 setores manufatureiros. Nossa contribuição para a literatura foi, inicialmente, identificar uma forma de medir a proximidade entre os setores produtivos que não seja através da coocorrência ou da comparação de categorias baseadas em classificações setoriais. Essas abordagens contribuíram para o debate, no entanto, elas não são com- 
pletamente aderentes para alguns países em desenvolvimento, como o Brasil. Por exemplo, classificações setoriais de intensidade tecnológica desenvolvidas com base nos países desenvolvidos - não são totalmente adequadas para o contexto inovativo brasileiro (Furtado; Carvalho, 2005), além disso, a pauta exportadora do Brasil não é um bom espelho da pauta de produção doméstica. Nesse contexto, sugerimos avaliar a proximidade setorial em termos das habilidades específicas do capital humano empregado nos setores da manufatura brasileira. Para tanto, elaboramos um novo índice de capacidades produtivas e tecnológicas visando capturar não apenas o número de empregados, mas a qualificação que eles possuem que contribuem para o desenvolvimento produtivo e tecnológico do setor em que atuam.

Outra contribuição refere-se ao método para calcular a proximidade. Diversos autores sugerem que há uma lacuna a ser preenchida no que diz respeito à construção de matrizes de vizinhança ${ }^{1}$ entre setores produtivos. Devido a essa ausência, a grande maioria dos trabalhos utiliza medidas de entropia baseadas em vetores para analisar a proximidade. Ao explorarmos as informações contidas na Pesquisa Industrial Anual - Empresa (PIA-Empresa) do IBGE, encontramos dados para construir uma matriz de vizinhança setorial, feita pelo IBGE exclusivamente para este estudo. Com essa matriz em mão, nós realizamos uma aplicação nova de métodos de econometria espacial para avaliar a distância cognitiva (e não geográfica, como o método é tradicionalmente empregado).

Após esta introdução, a seção 2 exibe o referencial teórico; a seção 3 apresenta como foram construídas as variáveis relacionadas ao capital humano e à matriz de proximidade setorial, assim como a metodologia de avaliação da dependência espacial; a seção 4 se dedica as análises descritivas e especificações econométricas; e a seção 5 conclui.

\section{Referencial teórico}

Para Penrose (1959), em seu clássico livro, a decisão de uma empresa diversificar sua produção envolve capacidades produtivas existentes e, em geral, a otimização direciona a produção para setores próximos tecnologi- 
camente que compartilham características produtivas. A questão em aberto é como identificar os fatores que tornam os setores próximos. Tentativas iniciais utilizaram a contagem de coocorrência de setores (em distintas agregações) utilizando informações: a) do fluxo de trabalhadores entre indústrias diferentes (Farjoun, 1994); b) de firmas que produzem produtos de setores distintos (Teece et al., 1992); e c) de áreas tecnológicas de patentes (Jaffe, 1986), entre outros. Estudos recentes sugerem medidas proxy para captar a relação entre os setores e seus efeitos sobre variáveis econômicas através de vantagem comparativa revelada (Hausmann et al., 2013) e entropia (Boschma; Iammarino, 2009; Bryce; Winter, 2009; Neffke; Henning, 2008). A seguir, há uma síntese da contribuição desses trabalhos quanto à proximidade na economia.

\subsection{Abordagens sobre a proximidade}

Algumas formas de proximidade não geográfica são difíceis de mensurar empiricamente, pois exigem o levantamento de inúmeras variáveis a respeito de tecnologias, capacidades produtivas, mercados, produtos, entre outros. Classificações setoriais e/ou de produtos são uma forma de identificar as relações entre setores - como da OECD (2003), que agrega os setores industriais em quatro categorias a partir da intensidade de gastos em P\&D em relação ao faturamento ou a taxonomia de Pavitt (1984), que possui quatro grupos de acordo com a origem e uso de inovações. Porém, tais classificações são muito agregadas e muitas vezes não correspondem à realidade de países em níveis de desenvolvimento econômico e tecnológico diferentes (Furtado; Carvalho, 2005). Além disso, há pouco fundamento teórico para supor que a estrutura hierárquica das classificações industriais explique as economias de escopo entre setores (Neffke; Henning, 2008).

Um dos primeiros autores que identificou claramente cinco dimensões da proximidade foi Boschma (2005). A primeira é a tradicional proximidade geográfica, que é dada pela distância espacial entre os agentes em termos absolutos ou relativos. A proximidade cognitiva é relacionada à base de conhecimento comum entre agentes; a organizacional abrange interações com atores que partilham o mesmo espaço e conhecimento; a social inclui relações entre agentes no nível microeconômico baseadas em confiança, parcerias e experiência; e a institucional envolve relações de interação no 
nível macroeconômico conduzidas por normas e regras - esta última foi inicialmente apresentada por Torre e Gilly (1999).

Outra importante contribuição conhecida como "espaço do produto", de Hidalgo et al. (2007) e Hausmann et al. (2013), mensura para mais de uma centena de países a proximidade no nível de classes de produtos do comércio internacional (Hidalgo et al., 2007). Eles usaram a coocorrência entre classes de produtos exportados com vantagem comparativa revelada como medida de proximidade. Os autores exibiram a proximidade dos produtos exportados por uma rede que eles chamaram de espaço do produto, transmitindo a ideia de vizinhança adotada neste artigo. Eles acreditam que a tecnologia, o capital, as instituições e habilidades necessárias para fazer novos produtos são mais facilmente adaptadas a partir de alguns produtos do que de outros, geralmente a partir de produtos próximos no espaço do produto (Hidalgo et al., 2007).

Essa nova abordagem foi bem-aceita e diversos autores realizaram o esforço de medi-la ou a analisaram em contextos específicos, inclusive os brasileiros. Gala et al. (2018) trabalharam com uma rede do comércio internacional de 762 classes de produtos para 101 países, para 2013. Os autores encontraram um padrão em que os produtos que estão no centro da rede, os quais possuem mais vínculos e nós densos, são manufaturados complexos exportados por países de elevada renda per capita; enquanto os países de baixa renda per capita exportam majoritariamente produtos mais simples e commoditizados que se situam na periferia da rede, com menos vínculos com os demais produtos. Britto et al. (2019) construíram o "espaço do produto" por categorias de intensidade tecnológica para cinco décadas entre 1965 e 2005 para Brasil e Coreia do Sul. Os autores verificaram que a Coreia do Sul foi mais bem-sucedida que o Brasil ao fazer a transição a partir dos produtos de menor intensidade tecnológica para os de alta intensidade tecnológica. Romero e Freitas (2018) identificaram nichos de produtos que poderiam aumentar a complexidade econômica do Brasil a partir de uma metodologia criativa que combinou indicadores de complexidade do produto, oportunidades de mercado e a proximidade do produto em relação à estrutura de produção do país. Os autores selecionaram 20 classes de produtos que se encontram próximas às capacidades produtivas existentes no país e com elevado potencial de mercado nacional e internacional, sugerindo aos formuladores de políticas quais segmentos produtivos poderiam ser alvo de políticas industriais. 
A abordagem da "variedade relacionada" é semelhante à do espaço do produto em termos de intuição - de que uma coisa leva a outra - e de aceitação pelos pesquisadores, porém ela é mensurada pelo método de entropia para setores produtivos. Baseados na ideia de que os "setores que estão relacionados em termos de competências complementares ou partilhadas" (Boschma; Iammarino, 2009, p. 292-293), diversos autores começaram a analisar como a variedade relacionada entre setores impacta as regiões, e não apenas os setores. A hipótese é que firmas de setores diferentes, mas relacionados tiram melhor proveito de spillovers de conhecimento do que firmas em setores não relacionados. Quatraro (2010) identificou que as externalidades inter-regionais exercem efeito sobre o crescimento da produtividade nas regiões italianas, pois nas regiões em que encontrou maior variedade relacionada entre os setores, o crescimento da produtividade foi mais rápido. Neffke et al. (2011) analisaram a entrada de novas empresas em regiões da Suécia e como a proximidade tecnológica as beneficia. Os autores mostraram que empresas de setores relacionados aos já existentes nas regiões têm maior chance de se estabelecerem, pois aproveitam a infraestrutura e os canais produtivos já estabelecidos. Ao usar a proximidade das habilidades para analisar a diversificação corporativa também para empresas suecas, Neffke e Henning (2008) descobriram que as empresas ingressam em setores fortemente relacionados às suas principais indústrias. Os autores estimaram que a probabilidade de uma empresa se diversificar em um setor fortemente relacionado a sua atividade principal é 123 vezes maior que a probabilidade de diversificar em setores não relacionados. Boschma e Iammarino (2009) avaliaram que o crescimento do emprego tem um efeito positivo em províncias italianas com setores relacionados entre si e que a variedade relacionada também contribui para o crescimento regional. Interessados no ponto de vista inovativo, Castaldi et al. (2015) investigaram como a variedade tecnológica afeta a produção de inovação de uma região. Com dados das categorias tecnológicas das patentes registradas nos EUA eles encontraram que a variedade relacionada aumenta a probabilidade de inovações em geral, enquanto a variedade não relacionada aumenta a probabilidade de inovações radicais.

Acima indicamos as principais abordagens e apenas algumas aplicações relacionadas à proximidade setorial foco deste estudo. Notamos que ainda há um desafio para estabelecer uma matriz de vizinhança - e não um vetor 
(entropia) ou uma proxy de produção - que possa representar a distância produtiva e tecnológica entre os setores de atividade, que é o ponto que o presente trabalho busca contribuir.

Em geral, o capital humano permeia muitos desses trabalhos, uma vez que capacidades produtivas estão diretamente relacionadas com capital humano, além do capital físico e esforço tecnológico (Lall, 1992). De forma mais detalhada, Lall (1992) e Viotti (2002) ajudaram a entender como as firmas assimilam tecnologias, desenvolvem e melhoram produtos, alteram seu processo produtivo e se adaptam a novas fontes de conhecimento. Segundo os autores, os conceitos de capacidades produtivas e tecnológicas estão no cerne desse arcabouço. Capacidades produtivas referem-se ao chão de fábrica e ao aprendizado do tipo learning-by-doing. Capacidades tecnológicas relacionam-se às atividades inovativas mais complexas, criação de novas tecnologias e modificações nucleares em produtos e processos existentes. Nesse sentido, pode-se considerar que o capital humano também está diretamente relacionado com transbordamentos de conhecimento e capacidades produtivas e tecnológicas entre setores industriais.

\section{Método, propostas e dados}

\subsection{Método}

Iremos avaliar a proximidade entre setores produtivos empregando métodos de econometria espacial. Essa é uma nova forma de averiguar a distância cognitiva que ainda não encontramos na literatura.

Os procedimentos metodológicos foram baseados em Lesage e Pace (2009), Almeida (2012) e Elhorst (2014). Para realizar o teste de autocorrelação de unidades espaciais empregaremos o índice I de Moran, o mais utilizado em estudo de cross-section. Em notação matricial consiste em (Almeida, 2012, p. 105):

$$
I=\frac{n}{\sum_{i} \Sigma_{j} w_{i j}} \frac{z^{\prime} W z}{z^{\prime} z}
$$

onde:

- né o número de unidades espaciais; 
- $z$ é a variável de interesse, um vetor dos resíduos de um modelo de Mínimos Quadrados Ordinários (MQO);

- $W_{z}$ representa os valores médios da variável de interesse padronizada nos vizinhos, definidos segundo uma matriz de ponderação espacial $W$;

- $\mathfrak{w}_{i j}$ são elementos da matriz de pesos espaciais referente ao setor $i$ e ao setor $j$;

- $\Sigma_{i} \Sigma_{j} w_{i j}$ indica a soma de todos os elementos da matriz de pesos espaciais $W$.

Segundo Almeida (2012, p. 105), a estatística do I de Moran é como um coeficiente de autocorrelação obtido pela autocovariância espacial do denominador, composta pelos produtos cruzados $z^{\prime} W z$ dividida pela variância dos dados $\left(z^{\prime} z\right)$. Observe que, se a matriz $W$ for normalizada na linha, o duplo somatório no denominador é igual a $n$, então, podemos reescrever a última equação como:

$$
I=\frac{z^{\prime} W z}{z^{\prime} z}
$$

A inferência para o Índice I de Moran baseia-se numa distribuição normal aproximada ao usar o valor $Z$ padronizado abaixo:

$$
Z(I)=\frac{I-E(I)}{D P(I)}
$$

onde $E(I)$ e $D P(I)$ são a média e o desvio-padrão, respectivamente, do I de Moran. O Índice varia entre -1 e 1 , onde valores negativos (positivos) indicam autocorrelação espacial negativa (positiva), e zero indica inexistência de padrão espacial nos dados, caso em que a hipótese nula de aleatoriedade espacial é aceita.

Utilizaremos o modelo autorregressivo espacial ou modelo de defasagem espacial (SAR), o qual incorpora um parâmetro rhô $(\rho)$ aos modelos lineares e é representado por:

$$
Y=\rho W Y+\varepsilon \text { ou } Y=\beta X+\rho W Y+\varepsilon
$$


onde:

- Y é um vetor $n \times 1$ de valores observados (a variável a ser explicada);

- $\rho$ é o coeficiente escalar autorregressivo;

- X é uma matriz nxk de variáveis explicativas (os controles);

- $\beta$ é um vetor px1 dos parâmetros das variáveis explicativas;

- Wé a matriz de pesos espaciais;

- $\varepsilon$ é um vetor $n x 1$ dos erros, onde $\varepsilon \sim N\left(\phi, I \sigma^{2}\right)$.

O modelo SAR incorpora a autocorrelação espacial como componente adicional do modelo. $\bigcirc$ coeficiente $\rho$ representa o efeito médio dos vizinhos sobre a variável dependente $(Y)$, isto é, se $\rho$ for estatisticamente diferente de zero significa que uma parcela da variação total de $Y$ é explicada pela dependência de cada observação de seus vizinhos (Almeida, 2012). Em outros termos, um $\rho$ positivo (negativo) significa que um alto valor de $Y$ nos setores vizinhos aumenta (diminui) o valor de $Y$ no setor $i$. Se não houver autocorrelação espacial, $\rho=0$, podemos estimar o modelo por $\mathrm{MQO}$. Já se $\rho \neq 0$, a estimativa por $\mathrm{MQO}$ produzirá estimadores viesados e inconsistentes.

Após manipulações algébricas, a última equação pode ser reescrita desta forma:

$$
Y=\left(I_{n}-\rho W\right)^{-1} X \beta+\left(I_{n}-\rho W\right)^{-1} \varepsilon
$$

A expressão acima requer que a matriz $\left(I_{n}-\rho W\right)^{-1}$ seja não singular para ser invertida (Almeida, 2012, p. 154-155).

Dado que $|\rho|<1$, pode-se reescrever $\left[I_{n}-\rho W\right]^{-1}$ como:

$$
\left[I_{n}-\rho W\right]^{-1}=I_{n}+\rho W+\rho^{2} W^{2}+\cdots
$$

Essa passagem é semelhante à matriz de coeficiente técnicos diretos e indiretos do modelo de insumo-produto, em que se capta um choque de produção setorial (efeito direto) e seu impacto na cadeia de fornecedores e subfornecedores (efeito indireto). Similarmente, no modelo SAR a variável dependente $(Y)$ pode ser explicada pelas variáveis $X$ e $\varepsilon$ (efeito direto) específicas a um setor e, também, por suas influências captadas pelas ligações em setores conectados pela matriz W (efeito indireto). 


\subsection{Propostas}

\section{"Vizinhança setorial"}

Consideraremos que os setores produtivos são próximos ou vizinhos quando possuem características compartilhadas relacionadas às tecnologias de produto e processos - baseado no conceito de Penrose (1959). A distância produtiva e tecnológica entre os setores será captada a partir de uma matriz de produção com dados de plantas multiprodutos. Dessa forma, abarcamos diretamente características produtivas necessárias para compartilhar meios de produção (entre eles, conhecimento e tecnologia). A similaridade que permite compartilhar características em termos tecnológicos e produtivos é resultante de capacitações acumuladas no tempo (Lundvall, 1992; Teece, 1982). Essa distância não pode ser tão grande (pois dificultaria a capacidade de compartilhar conhecimentos e técnicas) nem tão pequena (pois não haveria novidades a serem incorporadas) (Boschma; Iammarino, 2009; Nooteboom, 2000).

Para construir a matriz de vizinhança solicitou-se ao IBGE uma extração especial da PIA-Empresa (IBGE, 2013) correspondente ao valor bruto da produção industrial (VBPI) das unidades produtivas locais (UL) manufatureiras (ou plantas industriais), que produziram bens classificados em mais de um setor, discriminando em quais setores há registro de produção e seu respectivo valor (uma forma de coocorrência). Bryce e Winter (2009) também utilizaram informações de plantas multiprodutos americanas para estabelecer uma medida de proximidade. Contudo, para o Brasil essas informações não estão disponibilizadas publicamente, ${ }^{2}$ portanto conferem um caráter inédito a este trabalho.

Os dados da PIA-Empresa são coletados individualmente nas UL e posteriormente são agregados nos setores industriais. Cada UL declara o VBPI correspondente aos setores dos produtos fabricados. Se a UL produz produtos de um único setor, haverá informação em apenas um setor. Já se atua em mais de um, as informações são registradas em cada um dos respectivos setores. Assim se obtém o VBPI no setor principal (ou setor de origem) e em 2 Com um objetivo diferente, Alves e Ferreira (2018) também acessaram tabulações especiais do IBGE para avaliar empresas multiprodutos brasileiras (via combinação da PIA-Empresa e PIA-Produto, de 2005 a 2009). Eles mostraram que, embora as empresas multiprodutos fossem $37 \%$ das empresas do setor manufatureiro, elas representaram $81 \%$ da produção total, empregavam mais trabalhadores, eram mais propensas a exportar e tinham maior produtividade total dos fatores. 
cada um dos setores secundários. A classificação setorial utilizada é a CNAE 2.0 desagregada a três dígitos, que perfazem 103 setores manufatureiros. ${ }^{3}$

Então, será considerado que se uma planta industrial produz produtos típicos de alguns setores industriais, esses setores são vizinhos porque dependem da mesma base produtiva e tecnológica.

A produção total em um setor $j\left(V B P I T o y_{j}\right)$ será igual a:

$$
\operatorname{VBPITot}_{j}=V B P I_{j}+\sum V B P I_{k}
$$

sendo:

- $V B P I_{j}$ o valor bruto da produção industrial no setor principal;

- $V B P I_{k}$ o valor bruto da produção industrial nos setores secundários.

De posse dessas informações, foi construída uma matriz em que "um" indica o(s) setor(es) que cada um dos 103 setores atua(m) e "zero" indica em quais não atua(m). ${ }^{4} \mathrm{Na}$ sequência foi zerada a diagonal principal da matriz, já que um setor não é vizinho dele mesmo. Feito isso, foi verificado que seis setores não possuíam vizinhos. Para contornar esse problema e garantir que a matriz possua determinante diferente de zero, eles foram agregados considerando pares com similaridade tecnológica. ${ }^{5}$ Em seguida a matriz resultante foi somada com a sua transposta para obter uma matriz simétrica, que foi normalizada ao ser dividida pelo seu maior autovalor. Para as análises econométricas essa matriz foi padronizada na linha, obtendo assim a Matriz W do modelo.

\section{Índice de habilidades dos trabalhadores}

Criamos um "índice de habilidades" relacionado às capacidades produtivas e tecnológicas por ocupação. A proposição de um novo índice justifica-se

3 Utiliza-se a palavra setor para referir-se aos grupos da CNAE (desagregação a três dígitos). 4 Optamos por não realizar algum tipo de ponderação quanto ao valor da produção para manter todas as informações dos setores que conseguem compartilhar recursos.

5 Os setores agregados e seus respectivos códigos CNAE são: a) Coquerias e siderurgia; b) Mídias virgens, magnéticas e ópticas e equipamentos de informática; c) Aeronaves, veículos militares de combate e outros equipamentos de transporte; d) Aparelhos eletromédicos e instrumentos para uso médico, odontológico e artigos ópticos; e) Recondicionamento de motores e manutenção de máquinas e equipamentos. 
pelo interesse em medir capacidades produtivas e tecnológicas que podem ser compartilhadas entre setores que utilizam os mesmos trabalhadores para produzir mais de um produto, fazendo uso da definição de Boschma (2005) sobre proximidade cognitiva e organizacional. Dado que os trabalhadores atuam diretamente na produção de bens, suas habilidades produtivas e tecnológicas ajudam a explicar por que alguns bens são produzidos conjuntamente. Conforme apontou Teece (1982), o capital humano é um insumo comum para uma variedade de produtos e o que o diferencia são os atributos relacionados ao know-how que podem ser aplicados na produção. Farjoun (1994) também identificou que trabalhadores carregam consigo conhecimentos e técnicas que podem ser empregados em diferentes indústrias, as quais devem ter características compartilhadas para que esse conhecimento seja útil e aplicado em diferentes linhas de produção.

A construção do índice foi possível a partir do trabalho de Maciente (2013), que compatibilizou a classificação de ocupações americana (O-NET-SOC 2010)6 com a classificação de ocupações brasileiras (CBO 2002). ${ }^{7}$ A classificação americana indica as habilidades (skills) que cada ocupação demanda, de tal forma que podemos conhecer o perfil dos trabalhadores a partir da ocupação em que está empregado. Sobrinho e Azzoni (2016) fizeram procedimento semelhante e produziram uma medida de habilidades inovativas. Vale ressaltar que, embora a classificação da O-NET seja elaborada no contexto da economia americana, ela retrata características relacionadas estritamente à ocupação e não características pessoais dos trabalhadores (como qualidade da educação que recebeu ou aptidões pessoais). Assim, os requisitos para uma ocupação são os mesmos no Brasil e nos Estados Unidos. Apesar de a produtividade do trabalhador ou das máquinas empregadas nas fábricas diferir entre ambos os países, isso não deve contaminar a comparação dos requisitos da ocupação.

A criação do índice de habilidades foi realizada em duas etapas. Primeiro, baseado na literatura sobre a contribuição das habilidades no mercado de trabalho (Acemoglu, 1997; Doms et al., 1997; Fosfuri et al., 2001; Machin; Van Reenen, 1998; OECD, 2017) foram selecionadas 34 das 263 habilidades existentes, considerando como critério aquelas que proporcionam

6 O-NET (Occupational Information Network) é o banco de dados eletrônicos com a classificação ocupacional padrão produzida pelo USA Department of Labor.

7 Para maiores detalhes sobre o método de compatibilização e classificação das ocupações, ver Maciente (2013). 
desenvolvimento produtivo e tecnológico. De modo geral, elas estão relacionadas com coordenação e reorganização do processo produtivo, geração de ideias e soluções de problemas, diversificação da produção, geração de novos produtos, melhoramentos e adaptação de tecnologias e customização. Também foram selecionadas habilidades que traduzem características do processo inovativo da manufatura brasileira, o qual se concentra em inovações de processo e adaptação de produtos (Gusso, 2006; Simões et al., 2005). A lista com as habilidades selecionadas está na Tabela 1.

Tabela 1 Habilidades selecionadas para compor o índice de habilidades produtivas e tecnológicas

\begin{tabular}{|c|c|c|}
\hline & Nome da habilidade & Descrição \\
\hline 1 & Fluência de ideias & Sugerir um grande número de ideias. \\
\hline 2 & Originalidade & Sugerir ideias incomuns ou resolver problemas de forma criativa. \\
\hline 3 & $\begin{array}{l}\text { Sensibilidade a } \\
\text { problemas }\end{array}$ & $\begin{array}{l}\text { Reconhecer problemas ou identificar situações que podem dar } \\
\text { errado. }\end{array}$ \\
\hline 4 & Flexibilidade & Gerar, usar ou agrupar diferentes regras. \\
\hline 5 & $\begin{array}{l}\text { Habilidade em organizar } \\
\text { informações }\end{array}$ & Combinar e organizar informações com um padrão. \\
\hline 6 & $\begin{array}{l}\text { Habilidade em identificar } \\
\text { padrões }\end{array}$ & Identificar um padrão oculto. \\
\hline 7 & Capacidade investigativa & $\begin{array}{l}\text { Trabalhar com ideias, buscar fatos e resolver problemas mental- } \\
\text { mente. }\end{array}$ \\
\hline 8 & $\begin{array}{l}\text { Capacidade } \\
\text { empreendedora }\end{array}$ & $\begin{array}{l}\text { Iniciar e desenvolver projetos, liderar pessoas, tomar decisões e } \\
\text { lidar com riscos. }\end{array}$ \\
\hline 9 & Criatividade & Habilidade em desenvolver ideias próprias. \\
\hline 10 & Adaptabilidade & $\begin{array}{l}\text { Aceitar mudanças e trabalhar com diversidade no ambiente de } \\
\text { trabalho. }\end{array}$ \\
\hline 11 & Capacidade inovativa & Criatividade para desenvolver novas ideias e resolver problemas. \\
\hline 12 & Pensamento analítico & Analisar informações e usar a lógica para solucionar problemas. \\
\hline 13 & $\begin{array}{l}\text { Habilidades em } \\
\text { matemática }\end{array}$ & Domínio da matemática para resolver problemas. \\
\hline 14 & Habilidades em ciências & Domínio de métodos científicos para resolver problemas. \\
\hline 15 & Pensamento crítico & $\begin{array}{l}\text { Utilizar a lógica para identificar forças e fraquezas de alternativas } \\
\text { para solucionar problemas. }\end{array}$ \\
\hline 16 & Aprendizado ativo & $\begin{array}{l}\text { Entender novas informações para solucionar problemas atuais ou } \\
\text { futuros. }\end{array}$ \\
\hline
\end{tabular}


Tabela 1 (continuação)

\begin{tabular}{|c|c|c|}
\hline & Nome da habilidade & Descrição \\
\hline 17 & $\begin{array}{l}\text { Capacidade em solucio- } \\
\text { nar problemas complexos }\end{array}$ & $\begin{array}{l}\text { Identificar problemas complexos, revisar informações e avaliar } \\
\text { opções para obter soluções. }\end{array}$ \\
\hline 18 & $\begin{array}{l}\text { Habilidade em análise } \\
\text { operacional }\end{array}$ & Notar necessidades de produtos para criar um projeto. \\
\hline 19 & $\begin{array}{l}\text { Habilidade em gerar } \\
\text { tecnologias }\end{array}$ & $\begin{array}{l}\text { Gerar ou adaptar equipamentos e tecnologias para atender } \\
\text { usuários. }\end{array}$ \\
\hline 20 & $\begin{array}{l}\text { Habilidade em controle } \\
\text { de qualidade }\end{array}$ & $\begin{array}{l}\text { Conduzir testes e inspecionar produtos, serviços ou processos } \\
\text { para avaliar desempenho e qualidade. }\end{array}$ \\
\hline 21 & $\begin{array}{l}\text { Habilidade em avaliar } \\
\text { sistemas }\end{array}$ & $\begin{array}{l}\text { Identificar indicadores de desempenho de sistemas e ações } \\
\text { necessárias para melhorar o resultado. }\end{array}$ \\
\hline 22 & Administração e gestão & $\begin{array}{l}\text { Conhecimento dos princípios de gestão para planejamento estra- } \\
\text { tégico, alocação de recursos, coordenação de recursos humanos, } \\
\text { liderança e métodos de produção. }\end{array}$ \\
\hline 23 & $\begin{array}{l}\text { Conhecimentos } \\
\text { administrativos }\end{array}$ & Conhecimento de procedimentos e sistemas administrativos. \\
\hline 24 & $\begin{array}{l}\text { Capacidade de } \\
\text { customização de serviços }\end{array}$ & $\begin{array}{l}\text { Fornecer opções customizadas, avaliar necessidades dos clientes } \\
\text { e padrões de qualidade. }\end{array}$ \\
\hline 25 & $\begin{array}{l}\text { Conhecimento do } \\
\text { processo produtivo }\end{array}$ & $\begin{array}{l}\text { Conhecimento de matérias-primas, processos produtivos, con- } \\
\text { trole de qualidade, custos e técnicas para maximizar a produção } \\
\text { e distribuição. }\end{array}$ \\
\hline 26 & $\begin{array}{l}\text { Conhecimento de } \\
\text { engenharia e tecnologia }\end{array}$ & $\begin{array}{l}\text { Aplicação prática da ciência e tecnologia de engenharia, suas } \\
\text { técnicas, procedimentos e equipamentos para projetar e produzir. }\end{array}$ \\
\hline 27 & $\begin{array}{l}\text { Capacidade de } \\
\text { desenvolver projetos }\end{array}$ & $\begin{array}{l}\text { Domínio de técnicas, ferramentas e princípios envolvidos na } \\
\text { produção de plantas de precisão, projetos, desenhos. }\end{array}$ \\
\hline 28 & Domínio do idioma local & Conhecimento da estrutura e conteúdo do idioma local. \\
\hline 29 & $\begin{array}{l}\text { Domínio de língua } \\
\text { estrangeira }\end{array}$ & Conhecimento da estrutura e conteúdo de um idioma estrangeiro. \\
\hline 30 & $\begin{array}{l}\text { Capacidade de reter } \\
\text { informações }\end{array}$ & Observar, receber e obter outras informações de fontes relevantes. \\
\hline 31 & $\begin{array}{l}\text { Capacidade de identificar } \\
\text { informações }\end{array}$ & $\begin{array}{l}\text { Identificar informações por categoria, estimar, reconhecer dife- } \\
\text { renças ou similaridades e detectar mudanças. }\end{array}$ \\
\hline 32 & $\begin{array}{l}\text { Capacidade de analisar } \\
\text { dados }\end{array}$ & $\begin{array}{l}\text { Identificar princípios, razões ou fatos ao analisar as informações } \\
\text { ou dados em partes separadas. }\end{array}$ \\
\hline 33 & Pensamento criativo & $\begin{array}{l}\text { Desenvolver ou criar novas aplicações, ideias, sistemas ou } \\
\text { produtos. }\end{array}$ \\
\hline 34 & $\begin{array}{l}\text { Capacidade de atualizar } \\
\text { conhecimentos }\end{array}$ & $\begin{array}{l}\text { Manter-se atualizado tecnicamente e buscar aplicar novos conhe- } \\
\text { cimentos no trabalho. }\end{array}$ \\
\hline
\end{tabular}

Fonte: O-NET / U.S. Department of Labor. Elaboração própria. 
O segundo passo foi aplicar o método estatístico de Análise de Componentes Principais (ACP) para condensar as habilidades. Segundo Maciente (2013) as variáveis da O-NET possuem elevada autocorrelação, portanto permitem a aplicação do método de ACP para facilitar a interpretação dos resultados. Esse método assume a existência de certo número de variáveis latentes não observadas (chamadas de fatores), cuja variação explica o padrão de correlação de um conjunto maior de variáveis observadas (Conti et al., 2014; Hair et al., 1998).

Os procedimentos realizados e resultados do ACP serão apresentados de forma sintetizada. ${ }^{8}$ Realizou-se inicialmente o teste KMO (Kaiser-Meyer-Olkin) sob a amostra selecionada. O valor médio do KMO foi 0,9449 e, de acordo com Hair et al. (1998), resultados acima de 0,80 são considerados ideais para aceitar uma redução significante da amostra. Dos 34 componentes testados, 31 tiveram resultados acima de 0,80 e três componentes ficaram entre 0,76 e 0,79 . Confirmada a adequação da amostra, utilizou-se o método de extração de fatores via ACP. Para selecionar quantos fatores para o qual a amostra original será reduzida, considerou-se o critério da raiz latente e o Scree Test, que são os métodos tradicionalmente mais empregados (Hair et al., 1998).

O teste da raiz latente ou critério de Kaiser sugere que devem ser extraídos apenas os fatores com autovalor acima de 1, enquanto a análise gráfica descrita pelo Scree Test indica o corte no ponto de inflexão do gráfico. Hair et al. (1998) explicam que uma variância acumulada maior que $60 \%$ já indica uma amostra representativa. Seguindo tais critérios foram selecionados os primeiros quatro componentes (Figura 1) que explicam 90,3\% da variância acumulada.

\section{Figura 1 Teste da raiz latente}

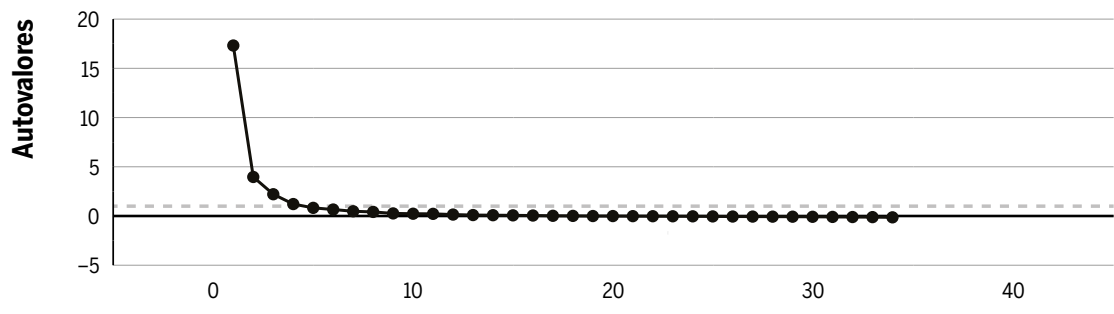

Número de fatores

Fonte: Elaboração própria.

8 Para uma análise completa dos procedimentos adotados, vide Tessarin (2018). 
No intuito de facilitar a interpretação dos fatores aplicou-se a rotação oblíqua (Promax) nos fatores a fim de determinar quais variáveis são mais carregadas em quais componentes. A rotação Promax aceita que as variáveis sejam correlacionadas e interdependentes (Hair et al., 1998), característica apresentada pelos componentes originais da presente amostra. As maiores cargas fatoriais foram consideradas para identificar e nomear cada um dos fatores. Tal identificação é feita à luz do conhecimento do pesquisador. Como a análise fatorial produziu um resultado coerente e adequado, essa tarefa foi facilitada.

A Tabela 2 indica o resultado obtido pelo método ACP, ou como pode-se interpretar, um conjunto de quatro habilidades que refletem as características desejadas das ocupações de interesse.

Tabela 2 Fatores resultantes da ACP das habilidades selecionadas na Tabela 1

\begin{tabular}{lr}
\hline & Descrição dos fatores renomeados \\
\hline Fator 1 & Capacidade analítica, de gerar conhecimento e soluções \\
\hline Fator 2 & Capacidade criativa e inovativa \\
\hline Fator 3 & Capacidade gerencial e empreendedora \\
\hline Fator 4 & Conhecimento de processo produtivo e geração de tecnologia \\
\hline
\end{tabular}

Fonte: Elaboração própria.

Seguindo Hair et al. (1998), realiza-se um cálculo ponderado pelo poder explicativo desses quatro fatores resultantes para obter apenas uma variável. Esta foi chamada de "índice de habilidades" das ocupações, que será adotado na ponderação do número de empregos em cada setor. ${ }^{9}$ Dessa forma, para cada setor, trabalhou-se com o número de empregos por ocupação ponderado pelo índice de habilidades, e não simplesmente com o número de empregos absoluto.

As ocupações que mais concentram essas habilidades são: físicos e engenheiros de várias especialidades, médicos de várias especialidades, pesquisadores, tecnólogos de várias áreas, entre outras. Nota-se que as profissões mais bem ranqueadas no índice proposto estão de acordo com a literatura (Gusso, 2006; Simões et al., 2005), que analisa as profissões relacionadas à mudança técnica nas empresas brasileiras.

9 De modo ilustrativo Tessarin (2018) apresentou as 100 ocupações mais bem posicionadas pelo índice de habilidades produtivas e tecnológicas. 


\subsection{Modelo de vizinhança setorial}

A seguir, estão indicadas as variáveis para testar a dependência entre setores produtivos.

Variável dependente: Número de ocupações ponderado pelo índice de habilidades produtivas e tecnológicas para o ano de 2013, por setor. Pretende-se avaliar se trabalhadores com habilidades produtivas e tecnológicas semelhantes apresentam relação de proximidade com trabalhadores com as mesmas habilidades de setores produtivos vizinhos.

Variáveis de controle: Selecionamos variáveis que explicam o desempenho produtivo, tecnológico e inovativo dos setores:

a) produtividade do trabalho: adotada por Timmer e Szirmai (2000) e Ark et al. (2008) como uma variável-chave para firmas e países crescerem e alcançarem melhores resultados econômicos;

b) porte das firmas: Schumpeter (1942) apontou que são as grandes firmas que conduzem a inovação e a mudança tecnológica. Singh e Whittington (1975) estabeleceram uma relação bem definida de que firmas maiores alcançam uma taxa de crescimento da produção superior às firmas de tamanhos menores;

c) abertura comercial: Helpman e Krugman (1985) e Romer (1994) afirmaram que o livre comércio traz maior eficiência para as firmas. Empresas que têm acesso a mercados internacionais possuem maior oportunidade de alcançar escala econômica ótima que possibilita amortizar investimentos críticos, como em $\mathrm{P} \& \mathrm{D}$;

d) parcela dos insumos e componentes importados: permite identificar a participação do comércio internacional nos insumos intermediários utilizados no processo produtivo. Helpman e Krugman (1985) e Romer (1994) apontaram que, ao obter acesso a uma maior variedade de insumos e de bens de capital no estado da arte e a um mercado potencial a ser explorado, a inserção no comércio internacional proporciona maior eficiência para as firmas;

e) investimento: Grossman e Helpman (1991) mostraram que investimentos em máquinas, equipamentos e novas tecnologias são decisivos para sustentar o crescimento da produção a longo prazo. Teece (1982) apontou que a utilização de bens de capital especializados estimula a produção compartilhada de bens diversificados;

f) participação dos salários na renda: Doms et al. (1997) e Machin e Van 
Reenen (1998) estimaram que, em geral, trabalhadores mais qualificados recebem salários maiores e contribuem mais para o incremento da produção.

A seguir está a apresentação das formulações específicas dos modelos econométricos aplicados. ${ }^{10}$

a) Mínimos Quadrados Ordinários (MQO)

$$
\begin{aligned}
& \text { NSkill }_{S}=\alpha+\delta \text { Produt }_{s}+\pi \text { Porte }_{S}+\beta \text { ACom }_{S}+\sigma \text { CII }_{S}+\varphi \text { Invest }_{S}+ \\
& +\mu S V A+\varepsilon
\end{aligned}
$$

b) Modelo autorregressivo espacial (SAR)

$$
\text { NSkill }_{S}=\sum X_{S} \beta+\sum \rho W_{S S} N_{S k i l l}+\varepsilon
$$

onde:

- Subscrito $s$ indica o setor da indústria de transformação (97 setores);

- NSkill : número de ocupações ponderado pelo índice de habilidades produtiva e tecnológica de cada ocupação;

- Produt $_{s}$ : produtividade do trabalho (razão entre valor adicionado e pessoal ocupado);

- Portes: porte das firmas (relação entre VBPI e número de estabelecimentos);

- $A \mathrm{Com}_{s}$ : abertura comercial (importação mais exportação dividido pelo VBPI);

- $C I I_{s}$ : coeficiente de insumos importados (parcela de insumos de origem importada em relação ao total de insumos utilizados no processo produtivo);

- Invest $t_{s}$ formação bruta de capital fixo (aquisições de bens de produção e suas melhorias excluída a depreciação);

- $S V A_{s}$ : participação do salário na renda (razão entre salários dos empregados ligados a produção e valor adicionado);

- $W_{s s}$ : matriz de vizinhança setorial;

- $X_{s}$ : controles setoriais;

10 Os dados de importações e exportações foram coletados da Funcex. As demais variáveis foram coletadas da PIA-Empresa 
$\rho$ : coeficiente autorregressivo, que capta autocorrelação espacial nos erros ou nas variáveis omitidas; $\mathrm{e}$

$\varepsilon$ : termo de erro.

Dessa forma empregaremos a tradicional técnica de modelos espaciais, porém de forma nova, para mensurar distâncias cognitivas.

\section{Resultados}

Na primeira etapa temos uma análise descritiva da matriz de vizinhança setorial, e na segunda, os resultados das estimações econométricas.

\subsection{Análise descritiva}

A Figura 2 traz a matriz quadrada dos 97 setores da indústria de transformação onde os quadrados pretos indicam os setores em que há registro de produção industrial. O setor principal está apresentado na linha e nas colunas estão os setores secundários. Os setores estão ordenados pelo nível de intensidade tecnológica da OECD (2003) e os quadrantes do mesmo nível tecnológico estão destacados (Figura 2). No quadrante superior-esquerdo estão setores de baixa e média-baixa tecnologia, e no inferior-direito os de alta e média-alta tecnologia.

Observe que a relação de vizinhança é mais presente dentro desses dois quadrantes entre setores de mesmo nível tecnológico. São 211 relações entre setores de baixa e média-baixa tecnologia e 118 entre alta e média-alta tecnologia. Já as relações entre setores de diferentes intensidades tecnológicas são mais escassas, as quais estão representadas nos quadrantes superior-direito e inferior-esquerdo. São 75 setores de baixa e média-baixa tecnologia que possuem produção secundária em setores de alta e média-alta e, no oposto, 80 setores de alta e média-alta produzem bens de setores de baixa e média-baixa tecnologia.

A presença maior de relações de vizinhança setorial parece indicar um padrão em que os setores se relacionam mais com vizinhos do mesmo nível tecnológico. Assim, pode-se considerar que a origem tecnológica do setor é um sinalizador para as relações de vizinhança devido à maior si- 
milaridade da base produtiva e tecnológica. Isso significa, por exemplo, que firmas que atuam no setor de laticínios têm maior probabilidade de ampliar sua produção para setores próximos, como para o setor de bebidas não alcoólicas. Ou que o setor de produtos eletrônicos tem maior probabilidade de passar a produzir itens do setor de equipamentos de informática do que do setor de papel e celulose, dado que os primeiros apresentam semelhanças tecno-produtivas e na base de conhecimento - seguindo a mesma intuição da literatura do espaço do produto (Hidalgo et al., 2007), da variedade relacionada (Boschma; Iammarino, 2009) e de Penrose (1959), conforme exposto na seção 2 .

Figura 2 Matriz de vizinhança setorial da indústria de transformação brasileira

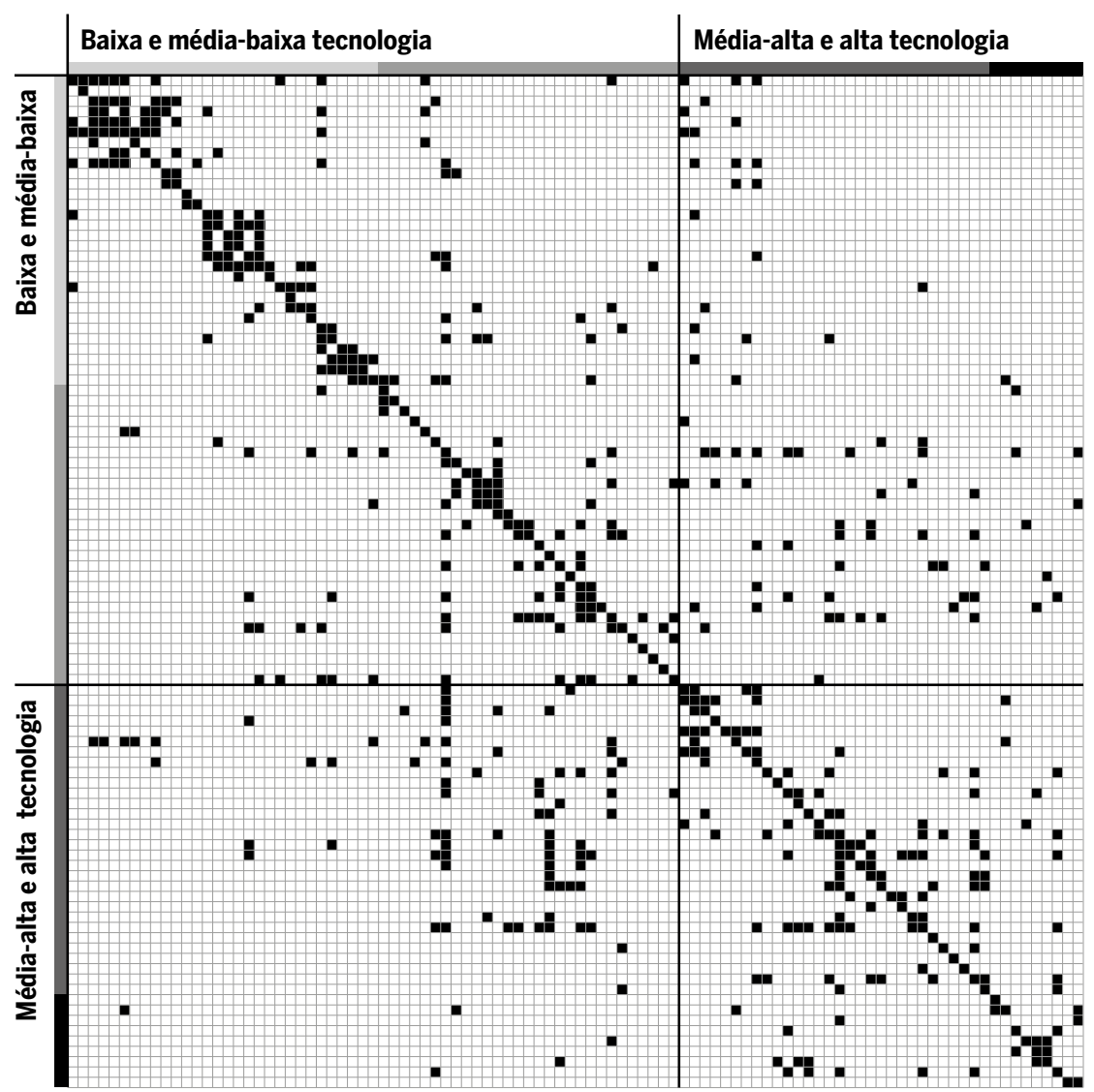

Fonte: Tabulação especial da PIA-Empresa 2013. Elaboração própria.

Nota: classificação setorial por intensidade tecnológica da OCDE. 
Alguns dos setores que mais se inter-relacionaram e formaram uma rede de vizinhança podem ser destacados em grupos: a) fabricação de conservas de frutas e legumes; óleos vegetais; laticínios; amiláceos; bebidas alcoólicas; e bebidas não alcoólicas; b) confecção de artigos do vestuários; tecelagem; acabamento de fios; calçados, e partes de calçados; c) siderurgia; metalurgia; fundição; artigos de cutelaria; e outros artigos de metal; d) fabricação de motores e bombas; máquinas e equipamentos de uso geral; tratores; máquinas-ferramentas; caminhões e ônibus.

No entanto, a rede completa não se limita aos setores mencionados. Apesar de a Figura 2 sugerir um padrão de vizinhança entre os setores manufatureiros, a avaliação estatística requerida será apresentada na próxima seção.

\subsection{Especificações econométricas}

Diferentemente das abordagens de coocorrência (Boschma; Iammarino, 2009; Farjoun, 1994; Neffke; Henning, 2008) ou do espaço do produto (Hidalgo et al., 2007), propomos avaliar a proximidade cognitiva via modelos de econometria espacial. Inicialmente verificamos a hipótese de aleatoriedade espacial a partir dos resíduos da regressão por MQO. Para detectar a autocorrelação espacial utilizou-se o Índice I de Moran.

Tabela 3 Índice I de Moran aplicado aos resíduos da regressão por MQO

\begin{tabular}{l|r|r}
\hline Observado & Expectativa & $\boldsymbol{p}$-valor \\
\hline $0,22269^{* * *}$ & $-0,02055$ & 0,00001 \\
\hline
\end{tabular}

Fonte: Elaboração própria.

Nota: ${ }^{* *}$ significante a $1 \%$.

A Tabela 3 mostra que o Índice I de Moran é positivo e, portanto, pode-se rejeitar a hipótese nula da aleatoriedade espacial num nível de significância de $1 \%$. Isso significa que há uma autocorrelação espacial positiva (Almeida, 2012), ou seja, ocupações ponderadas pelas habilidades produtivas e tecnológicas tendem a estar circundadas por altos valores dessa variável em setores vizinhos, ao passo que baixos valores tendem a estar rodeados também por baixos valores em setores vizinhos. Assim, o número de ocupações ponderadas por habilidades produtivas e tecnológicas apresenta 
uma similaridade no modelo de regressão, reafirmando a inferência feita a partir da Figura 2.

Figura 3 Diagrama de dispersão de Moran dos resíduos da regressão por MQO

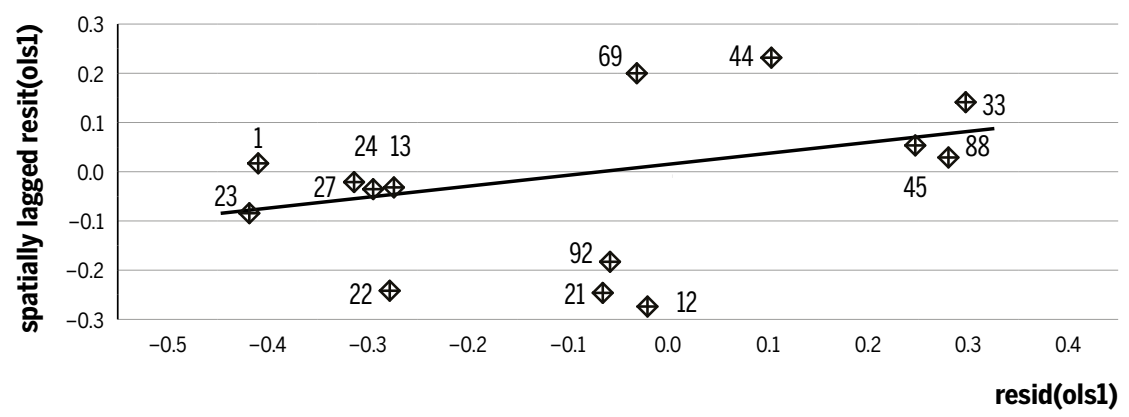

Fonte: Elaboração própria.

O diagrama de dispersão de Moran (Figura 3) apresenta concentrações mais densas nos quadrantes baixo-baixo (BB) e alto-alto (AA), ou seja, vizinhos parecidos são circundados por vizinhos parecidos. As aglutinações nos quadrantes baixo-alto (BA) e alto-baixo ( $A B$ ) são menos intensas e indicam o caso inverso, em que vizinhos diferentes são circundados por vizinhos diferentes, as quais são menos frequentes. Farjoun (1994) também havia argumentado que é o capital humano com qualificações parecidas que viabiliza compartilhar e transferir recursos semelhantes entre os setores. Neffke e Henning (2008) verificaram que o fluxo de trabalhadores entre os setores apresenta uma similaridade em suas habilidades, que depende também da compatibilidade entre culturas corporativas e de redes sociais.

Como constatou-se que os resíduos da regressão por MOO possuem autocorrelação espacial, inviabilizou-se o prosseguimento da análise por MQO. Para casos em que há autocorrelação espacial: a) na variável dependente, as estimativas de $\mathrm{MQO}$ são viesadas e inconsistentes ou b) no termo de erro, não há viés nem inconsistência, mas o estimador de MQO deixa de ser o mais eficiente; o que direciona para a utilização de outros modelos.

Sendo assim, foi realizado o Teste LM (Multiplicador de Lagrange) baseado na estimação por máxima verossimilhança (Tabela 4), conforme indicado por Anselin (2003) para fazer a escolha da especificação mais correta. Enquanto resultado, o Teste LM apontou o modelo SAR como mais apropriado. 
Tabela 4 Teste LM para escolha do modelo espacial

\begin{tabular}{lr|r}
\hline Modelo & Estatísticas & $\boldsymbol{p}$-valor \\
\hline LMerr (SEM) & 13,331842 & 0,0003 \\
\hline LMlag (SAR) & 22,927108 & 0,0000 \\
\hline RLMerr (RSEM) & 0,078423 & 0,7794 \\
\hline RLMlag (RSAR) & 9,673689 & 0,0019 \\
\hline SARMA & 23,005530 & 0,0000 \\
\hline
\end{tabular}

Fonte: Elaboração própria.

Tabela 5 Estimativas dos modelos econométricos

\begin{tabular}{lrrr}
\hline & MQ0 & SAR & SAR-Robusto \\
\hline Intercepto & $1,16500^{* * *}$ & $0,40205^{* *}$ & $0,48537^{* * *}$ \\
\hline Produtividade & $(8,647 \mathrm{e}-02)$ & $(1,329 \mathrm{e}-02)$ & $(8,011 \mathrm{e}-03)$ \\
\hline Porte das firmas & $0,00238^{* * *}$ & $0,00189^{* * *}$ & $0,00194^{* * *}$ \\
& $(2,995 \mathrm{e}-04)$ & $(7,3190 \mathrm{e}-13)$ & $(1,99 \mathrm{e}-10)$ \\
\hline Abertura comercial & $-1,081 \mathrm{e}-08$ & $-8,9798 \mathrm{e}-09$ & $-9,18 \mathrm{e}-09$ \\
\hline Coef. de insumos & $(2,044 \mathrm{e}-08)$ & $(0,59732)$ & $(0,29099)$ \\
importados & $0,02837^{* *}$ & 0,01404 & $0,01560^{*}$ \\
\hline Investimento & $(1,274 \mathrm{e}-02)$ & $(1,886 \mathrm{e}-01)$ & $(7,091 \mathrm{e}-02)$ \\
\hline Parcela dos salários & $0,21970^{* *}$ & $0,14585^{*}$ & $0,15391^{* *}$ \\
no VA & $(8,963 \mathrm{e}-02)$ & $(5,098 \mathrm{e}-02)$ & $(3,457 \mathrm{e}-02)$ \\
\hline Rhô & $-1,883 \mathrm{e}-08^{* * *}$ & $1,478 \mathrm{e}-08^{* * *}$ & $-1,522 \mathrm{e}-08^{* * *}$ \\
& $(4,400 \mathrm{e}-09)$ & $(9,2040 \mathrm{e}-05)$ & $(1,44 \mathrm{e}-04)$ \\
\hline Sigma & $0,4440^{* *}$ & $0,31596^{* *}$ & $0,32993^{* * *}$ \\
\hline Sigma ${ }^{2}$ & $(1,712 \mathrm{e}-01)$ & $(2,708 \mathrm{e}-02)$ & $(3,196 \mathrm{e}-03)$ \\
\hline AIC & & $0,54579^{* * *}$ & $0,48621^{* * *}$ \\
\hline Log Likelihood & & $(7,35 \mathrm{e}-07)$ & $(2,79 \mathrm{e}-05)$ \\
\hline $\mathbf{R}^{2}$ & 0,6103 & & 0,12878 \\
\hline $\mathbf{R}^{2}$ ajustado & 26,06 & & 0,01658 \\
\hline Estatística F & $(0,00001)$ & $-109,84$ & 0,05061 \\
\hline Moran dos resíduos & & 63,92085 & $(0,1475)$ \\
\hline & & & \\
\hline
\end{tabular}

Fonte: Elaboração própria.

Nota: $n=97$ observações. ${ }^{* *}$ significante a $1 \%$. ${ }^{*}$ significante a $5 \%$. ${ }^{*}$ significante a $10 \%$. 
$\mathrm{Na}$ Tabela 5 estão os resultados das especificações econométricas. As variáveis de controle selecionadas no modelo $\mathrm{MOO}$ apresentam um poder explicativo de $63 \%$ e apenas o porte das firmas não teve significância estatística, possivelmente devido à baixa variância, já as demais variáveis explicativas são significantes a pelo menos $5 \%$.

Nota-se que o coeficiente que indica autocorrelação espacial - rhô $(\rho)$ nos modelos SAR e SAR Robusto - foi estatisticamente diferente de zero ao nível de $1 \%$ de significância e positivo (Tabela 5). Essa autocorrelação espacial é forte e não marginal, dado que $\rho$ ficou próximo a 0,5 (no SAR, $\rho=0,546$ e no SAR Robusto $\rho=0,486$ ). Isso coloca em evidência a dependência espacial no âmbito setorial da manufatura brasileira, conforme procurou-se analisar inicialmente. Pode-se interpretar que as ocupações com habilidades produtivas e tecnológicas estão sendo influenciadas positivamente pelos resultados encontrados nos setores vizinhos. Esse efeito entre setores próximos é semelhante aos resultados de Farjoun (1994), que mostrou que os grupos de setores para os quais a empresa diversifica se relacionam entre si nos tipos de habilidades e conhecimentos humanos exigidos em cada setor. Outros trabalhos apontaram que o fluxo de trabalhadores que mudam de setor também possui uma relação positiva com suas habilidades (Boschma; Iammarino, 2009; Neffke; Henning, 2008; Teece et al., 1992).

Como verificado pelo Teste LM (Tabela 4), o modelo mais adequado é o SAR. Nesse modelo, exceto para porte das firmas e abertura comercial, as demais variáveis de controle apresentaram-se estatisticamente significantes. No Brasil, verificam-se muitas vezes configurações onde uma grande empresa se instala e atrai várias outras de menor porte, nesse sentido, o porte pode não ser significativo para medir os efeitos da vizinhança. $\bigcirc$ resultado indica que o número de ocupações com habilidades produtivas e tecnológicas é explicado, além de outras variáveis, pelas ocupações com habilidades parecidas presentes nos setores vizinhos. Ademais, o número de ocupações com tais habilidades tende a variar positivamente com produtividade, coeficiente dos insumos importados, participação dos salários na renda e investimento. Se um setor emprega mão de obra com alto nível de habilidades relacionadas às capacidades produtivas e tecnológicas, ele atrai outros setores que possuem o mesmo tipo de mão de obra. Dessa forma podemos entender que os spillovers de conhecimento e transbordamentos tecnológicos encontram maior facili- 
dade para circular e serem replicados entre setores próximos na matriz de vizinhança setorial, em linha com a argumentação de Teece et al. (1992). Por outro lado, setores que possuem trabalhadores com baixo nível das habilidades avaliadas não aparentam ser próximos dos subsetores que apresentam maior nível de habilidades, provavelmente, devido à maior complexidade das técnicas e conhecimentos requeridos em seu processo produtivo. Neffke e Henning (2008) também encontraram que habilidades dos trabalhadores semelhantes dominam as ligações entre setores para os quais as firmas se diversificam.

A partir da nossa suposição inicial de que os setores produtivos são relacionados quando possuem características compartilhadas associadas às tecnologias de produto e processos, encontramos assim uma forma de medir essa proximidade ou vizinhança entre eles. Através de nossos resultados podemos sugerir que o capital humano relacionado às habilidades produtivas e tecnológicas é importante não apenas para a estratégia das empresas, mas também para viabilizar a absorção de transbordamentos tecnológicos e de conhecimentos por ser o elo que filtra e internaliza as atividades desenvolvidas em seu entorno por trabalhadores com o mesmo nível de habilidades.

Os modelos SAR são capazes de capturar os efeitos da reprodução de determinados eventos sobre seus vizinhos (Almeida, 2012). Mudanças numa variável do próprio setor afetam-no de forma direta, enquanto mudanças em setores vizinhos o afetam de forma indireta, através de efeitos feedbacks. Pode-se calcular o efeito marginal total de tais mudanças pela soma do efeito marginal direto e do efeito marginal indireto. A Tabela 6 resume esses efeitos.

A produtividade e o investimento apresentaram efeitos marginais significantes tanto direto, indireto como total, sendo os efeitos direto e indireto de dimensão similar. Geralmente, setores mais produtivos empregam mão de obra mais qualificada, um resultado esperado. $O$ efeito marginal do investimento, embora pequeno tem sinal negativo, o que pode indicar que os equipamentos adquiridos poupam mão de obra com habilidades produtivas e tecnológicas. Ressalta-se novamente que a mão de obra em questão abarca empregos com habilidades produtivas e tecnológicas, então a substituição de postos de trabalho, por definição, acarreta redução desses funcionários, os quais estão diretamente ligados ao uso dos bens de capital. 
Tabela 6 Efeitos marginais do modelo SAR

\begin{tabular}{lrrr}
\hline & Efeito direto & Efeito indireto & Efeito total \\
\hline Produtividade & $\begin{array}{r}0,00197^{* * *} \\
(1,3967 \mathrm{e}-13)\end{array}$ & $\begin{array}{r}0,00218^{* *} \\
(2,3659 \mathrm{e}-02)\end{array}$ & $\begin{array}{r}0,00415^{* * *} \\
(1,0325 \mathrm{e}-04)\end{array}$ \\
\hline Porte das firmas & $\begin{array}{r}-9,404 \mathrm{e}-09 \\
(5,8997 \mathrm{e}-01)\end{array}$ & $\begin{array}{r}-1,037 \mathrm{e}-08 \\
(6,3101 \mathrm{e}-01)\end{array}$ & $\begin{array}{r}-1,977 \mathrm{e}-08 \\
(6,0365 \mathrm{e}-01)\end{array}$ \\
\hline Abertura comercial & 0,01470 & 0,01621 & 0,03091 \\
\hline Coeficiente de & $(1,8908 \mathrm{e}-01)$ & $(2,9017 \mathrm{e}-01)$ & $(2,2249 \mathrm{e}-01)$ \\
insumos importados & $0,15273^{* *}$ & 0,16837 & $0,32111^{*}$ \\
\hline Investimento & $(4,9266 \mathrm{e}-02)$ & $(1,6186 \mathrm{e}-01)$ & $(8,3462 \mathrm{e}-02)$ \\
\hline Parcela de & $-1,547 \mathrm{e}-08^{* * *}$ & $-1,706 \mathrm{e}-08^{* *}$ & $-3,253 \mathrm{e}-08^{* * *}$ \\
salários no VA & $(7,2748 \mathrm{e}-05)$ & $(3,6615 \mathrm{e}-02)$ & $(1,9615 \mathrm{e}-03)$ \\
\hline
\end{tabular}

Fonte: Elaboração própria.

Nota: Os termos entre parênteses representam o p-valor. ${ }^{* *}$ significante a $1 \% .{ }^{*}$ significante a $5 \%$. ${ }^{*}$ significante a $10 \%$.

O coeficiente de insumos importados e parcela dos salários na renda são significativos nos efeitos diretos e no total. Nesses casos, o efeito total tem variância alta e é relativamente capaz de explicar no nível de $10 \%$ de significância que existe um efeito indireto gerado sobre os vizinhos. Já os efeitos marginais quanto ao porte e abertura comercial não se mostraram estatisticamente significantes. Dessa forma, pode-se inferir que setores vizinhos tendem a ser beneficiados principalmente através de ações que modifiquem a produtividade e os investimentos.

\section{Considerações finais}

Este trabalho investigou a proximidade setorial na indústria de transformação brasileira. Como é um tema recente, buscou-se contribuir com a literatura ao sugerir uma medida de distância cognitiva entre os setores produtivos. Uma das novidades do artigo foi empregar dados de plantas multiprodutos - em geral, informação escassa no Brasil - para construir uma matriz de vizinhança setorial. Esses dados foram obtidos para cerca de 100 setores manufatureiros via PIA-Empresa do IBGE exclusivamente para este estudo. Outro ponto inovador foi a elaboração de um índice de 
habilidades produtivas e tecnológicas relacionadas à ocupação do trabalhador. $O$ intuito foi explicar como trabalhadores com habilidades específicas (e não apenas o número de empregos) estão relacionados à geração de oportunidades produtivas e tecnológicas nos setores manufatureiros. Com esse índice foi possível verificar que setores com trabalhadores que possuem habilidades produtivas e tecnológicas são próximos de setores com o mesmo tipo de profissionais, os quais impactam positivamente, em especial, produtividade e investimento em capital fixo.

Para chegar a esses resultados empregou-se uma nova abordagem aos tradicionais métodos de econometria espacial. Concluiu-se que os setores da manufatura brasileira são autocorrelacionados e estatisticamente significantes (no nível de 1\%). Pôde-se ver que as relações de vizinhança são mais frequentes entre setores produtivos com conteúdo tecnológico similar. Concluiu-se que variações positivas nas ocupações com habilidades produtivas e tecnológicas em um setor geram efeitos positivos, em sua maioria, sobre os setores que fazem parte de sua vizinhança.

Este estudo ajuda a compreender que ações orientadas a um setor podem transbordar efeitos para outros setores que utilizam base produtiva e tecnológica semelhantes. Isto é, o impacto de políticas específicas é na verdade mais amplo quando se considera a vizinhança que o setor engloba. Algumas estratégias de desenvolvimento produtivo, tecnológico ou geração de empregos podem ser alcançadas mais rapidamente ao focarem nos setores que possuem uma região de vizinhança densa nas características que se deseja influenciar. Análises futuras podem ser empreendidas para o melhor entendimento acerca do perfil do trabalhador envolvido e/ ou identificar os blocos de setores em que a relação de proximidade é mais forte e o modo como os transbordamentos se distribuem.

\section{Referências}

ACEMOGLU, D. Training and innovation in an imperfect labour market. Review of Economic Studies, v. 64, n. 3, p. 445-464, 1997.

ALMEIDA, E. Econometria espacial aplicada. Campinas: Editora Alínea, 2012.

ALVES, J. D.; FERREIRA, M. S. Multiproduct firms, firm dynamics, and the productive mix of Brazilian manufacturing firms. Estudos Econômicos, v. 48, n. 3, p. 349-389, 2018.

ANSELIN, L. Spatial externalities, spatial multipliers, and spatial econometrics. International Regional Science Review, v. 26, n. 2, p. 153-166, 2003. 
ARK, B. VAN; MAHONY, M. O.; TIMMER, M. P. The productivity gap between Europe and the United States: Trends and causes. Journal of Economic Perspectives, v. 22, n. 1, p. 25-44, 2008.

BOSCHMA, R. Proximity and innovation: A critical assessment. Regional Studies, v. 39, n. 1, p. 61-74, 2005.

BOSCHMA, R.; IAMMARINO, S. Related variety, trade linkages, and regional growth in Italy. Economic Geography, v. 85, n. 3, p. 289-311, 2009.

BRITTO, G.; ROMERO, J. P.; FREITAS, E.; COELHO, C. The great divide: Economic complexity and development paths in Brazil and the Republic of Korea. Cepal Review, v. 127, p. 191-213, 2019.

BRYCE, D. J.; WINTER, S. G. A general interindustry relatedness index. Management Science, v. 55 , n. 9 , p. $1570-1585,2009$.

CASTALDI, C.; FRENKEN, K.; LOS, B. Related variety, unrelated variety and technological breakthroughs: An analysis of US state-level patenting. Regional Studies, v. 49, n. 5, p. 767-781, 2015.

CONTI, G.; FRÜHWIRTH-SCHNATTER, S.; HECKMAN, J.; PIATEK, R. Bayesian exploratory factor analysis. Journal of Econometrics, v. 183, n. 1, p. 31-57, 2014.

DINIZ, C. C.; CROCCO, M. A. Reestruturação econômica e impacto regional: o novo mapa da indústria brasileira. Nova Economia, v. 6, n. 1, p. 77-103, 1996.

DOMS, M.; DUNNE, T.; TROSKE, K. R. Workers, wages, and technology. Quarterly Journal of Economics, v. 112, n. 1, p. 253-290, 1997.

ELHORST, P. Spatial econometrics: from cross-sectional data to spatial. London: Springer, 2014.

FARJOUN, M. Beyond industry boundaries: human expertise, diversification and resourcerelated industry groups. Organization Science, v. 5, n. 2, p. 185-200, 1994.

FOSFURI, A.; MOTTA, M.; RØNDE, T. Foreign direct investment and spillovers through workers' mobility. Journal of International Economics, v. 53, n. 1, p. 205-222, 2001.

FURTADO, A. T.; CARVALHO, R. DE Q. Padrões de intensidade tecnológica da indústria brasileira: um estudo comparativo com os países centrais. São Paulo em Perspectiva, v. 19, n. 1, p. 70-84, 2005.

GALA, P.; CAMARGO, J.; FREITAS, E. The Economic Commission for Latin America and the Caribbean was right: scale-free complex networks and core-periphery patterns in world trade. Cambridge Journal of Economics, v. 42, p. 633-651, 2018.

GROSSMAN, G. M.; HELPMAN, E. Innovation and Growth in the Global Economy. Economica, v. 60, n. 239, p. 373, 1993.

GUSSO, D. A. Agentes da inovação: quem os forma, quem os emprega? In: DE NEGRI, J. A.; DE NEGRI, F.; COELHO, D. (Org.). Tecnologia, Exportação e Emprego. Brasília: Ipea, 2006. p. 397-444.

HAIR, J. F.; BLACK, W. C.; BABIN, B. J.; ANDERSON, R. E. Multivariate data analysis. 5. ed. New Jersey: Pearson Prentice Hall, 1998.

HAUSMANN, R.; HIDALGO, C.; BUSTOS, S.; COSCIA, M.; SIMOES, A.; YILDIRIM, M. A. The Atlas of economic complexity: mapping paths to prosperity. Cambridge, Massachusetts, 
London: MIT Press, 2013.

HELPMAN, E.; KRUGMAN, P. R. Market structure and foreign trade. Cambridge, Massachussets: MIT Press, 1985.

HIDALGO, C.; KLINGER, B.; BARABÁSI, A.-L.; HAUSMANN, R. The Product Space conditions the development of nations. Science, v. 317, n. 5837, p. 482-487, 2007.

IBGE. Pesquisa Industrial Anual Empresa: 2013. 32. ed. Rio de Janeiro: IBGE, 2013.

JAFFE, A. B. Technological opportunity and spillovers of R\&D: evidence from firms' patents, profits, and market value. The American Economic Review, v. 76, n. 5, p. 984-1001, 1986.

LALL, S. Technological capabilities and industrialization. World Development, v. 20, n. 2, p. $165-186,1992$.

LESAGE, J.; PACE, K. Introduction to spatial econometrics. Florida: Chapman \& Hall/CRC Press, 2009.

LUNDVALL, B.-Å. National Systems of Innovation: towards a theory of innovation and interactive learning. London: Pinter, 1992.

MACHIN, S.; VAN REENEN, J. Technology and changes in skill structure: evidence from seven OECD countries. The Quarterly Journal of Economics, v. 113, n. 4, p. 1215-1244, 1998.

MACIENTE, A. N. The determinants of agglomeration in Brazil: Input-output, labor and knowledge externalities. 2013. $282 \mathrm{f}$. Dissertation. University of Illinois at Urbana-Champaign, 2013.

MORCEIRO, P. C. Evolution and sectoral competiveness of the Brazilian manufacturing industry. In: AMANN, E.; AZZONI, C. R.; BAER, W. (Org.). The Oxford Handbook of the Brazilian Economy. New York: Oxford University Press, 2018.

NEFFKE, F.; HENNING, M. S. Revealed relatedness mapping industry space. DRUID Conference, v. June, p. 1-33, 2008.

NEFFKE, F.; HENNING, M. S.; BOSCHMA, R. How do regions diversify over time? Industry relatedness and the development of new growth paths in regions. Economic Geography, v. 87 , n. 3, p. 237-265, 2011.

NOOTEBOOM, B. Learning and innovation in organizations and economies. Oxford: Oxford University Press, 2000.

OECD. Getting skills right: skills for jobs indicators. Paris: OECD, 2017.

OECD. Science, Technology and Industry Scoreboard 2003. Paris: OECD, 2003.

PAVITT, K. Sectoral patterns of technical change: Towards a taxonomy and a theory. Research Policy, v. 13, p. 343-373, 1984.

PENROSE, E. The theory of the growth of the firm. Fourth ed. New York: Oxford University Press, 1959.

QUATRARO, F. Knowledge coherence, variety and economic growth: Manufacturing evidence from Italian regions. Research Policy, v. 39, n. 10, p. 1.289-1.302, 2010.

RODRIK, D. Premature deindustrialization. Journal of Economic Growth, v. 21, n. 1, p. 1-33, 2016.

ROMER, P. The origins of endogenous growth. The Journal of Economic Perspectives, v. 8, n. 1, 
p. 3-22, 1994.

ROMERO, J. P.; FREITAS, E. Setores promissores para o desenvolvimento do Brasil: complexidade e espaço do produto como instrumentos de política. In: ANDRADE, M. V.; ALBUQUERQUE, E. DA M. E (Org.). Alternativas para uma crise de múltiplas dimensões. Belo Horizonte: CEDEPLAR, 2018. p. 358-374.

SCHUMPETER, J. A. Capitalism, socialism \& democracy. London; New York: Routledge, 1942.

SIMÕES, R.; OLIVEIRA, A.; GITIRANA, A.; CUNHA, J.; CAMPOS, M.; CRUZ, W. A geografia da inovação: uma metodologia de regionalização das informações de gastos em $P \& D$ no Brasil. Revista Brasileira de Inovação, v. 4, n. 1, p. 157-185, 2005.

SINGH, A.; WHITTINGTON, G. The size and growth of firms. The Review of Economic Studies, v. 42 , n. 1 , p. $15-26$, jan. 1975.

SOBRINHO, E. M. G.; AZZONI, C. R. Potencial inovativo da indústria nas regiões brasileiras. Revista Brasileira de Inovação, v. 15, n. 2 jul/dez, p. 275-304, 2016.

TEECE, D. J. Towards an economic theory of the multiproduct firm. Journal of Economic Behavior and Organization, v. 3, n. 1, p. 39-63, 1982.

TEECE, D. J.; RUMELT, R. P.; DOSI, G.; WINTER, S. G. Understanding corporate coherence: theory and evidence. Journal of Economic Behavior and Organization, v. 23, p. 1-30, 1992.

TESSARIN, M. S. O papel da inovação, diversificação e vizinhança setorial no desenvolvimento industrial recente do Brasil. 180 p. Tese (Doutorado) - Faculdade de Economia, Administração e Contabilidade, Universidade de São Paulo, São Paulo, 2018.

TIMMER, M. P.; SZIRMAI, A. Productivity growth in Asian manufacturing: the structural bonus hypothesis examined. Structural Change and Economic Dynamics, v. 11, n. 4, p. 371$392,2000$.

TORRE, A.; GILLY, J.-P. On the analytical dimension of proximity dynamics. Regional Studies, v. 34, n. 2, p. 169-180, 1999.

VIOTTI, E. B. National Learning Systems A new approach on technological change in late industrializing economies and evidences from the cases of Brazil and South Korea. Technological Forecasting \& Social Change, v. 69, p. 653-680, 2002.

\section{Sobre os autores}

Milene Simone Tessarin-milenetessarin@alumni.usp.br

DST/NRF South African Research Chair (SARChI) in Industrial Development, University of Johannesburg, Johannesburg, África do Sul.

ORCID: https://orcid.org/0000-0003-2922-8335.

Paulo César Morceiro - paulo.morceiro@alumni.usp.br

DST/NRF South African Research Chair (SARChI) in Industrial Development, University of Johannesburg, Johannesburg, África do Sul.

ORCID: https://orcid.org/0000-0002-9548-0996.

André Luiz Squarize Chagas - achagas@usp.br

Faculdade de Economia, Administração e Contabilidade, Universidade de São Paulo (FEA/USP), São Paulo, SP, Brasil. ORCID: https://orcid.org/0000-0001-7870-8736.

Joaquim José Martins Guilhoto - joaquim.guilhoto@oecd.org

Economista, Organização para Cooperação e Desenvolvimento Econômico (OCDE), Paris, França.

Universidade de São Paulo, São Paulo, SP, Brasil. 
ORCID: https://orcid.org/0000-0002-7098-1209.

Agradecemos os comentários recebidos dos pareceristas anônimos e do editor da Nova Economia, que contribuíram para melhorias no artigo, tornando-o mais claro e consistente. Também agradecemos à Fundação Instituto de Pesquisas Econômicas (FIPE) pelo apoio financeiro e aos membros do Núcleo de Economia Regional e Urbana da USP (NEREUS-USP) pelas discussões. O presente trabalho foi realizado com apoio da Coordenação de Aperfeiçoamento de Pessoal de Nível Superior (CAPES) - Código de Financiamento 001. O autor Joaquim José Martins Guilhoto destaca que o conteúdo desta publicação expressa a visão deste autor e não necessariamente representa a visão da OCDE ou dos seus países membros.

\section{Sobre 0 artigo}

Recebido em 23 de abril de 2019. Aprovado em 03 de abril de 2020. 